\title{
The Impact of Layer Number on Stray Inductance of DC-link Busbar in Power Converters
}

\author{
Yi-feng $\mathrm{Zhu}^{1, *}$, Zheng Zheng ${ }^{1}$ and Qiong-xuan $\mathrm{GE}^{2}$ \\ ${ }^{1}$ School of Electrical Engineering and Automation, He'nan Polytechnic University, JiaoZuo City, Henan Provence, \\ China \\ ${ }^{2}$ Key Laboratory of Power Electronics and Electric Drive, Institute of Electrical Engineering, Chinese Academy of Sci- \\ ences, Beijing, China
}

\begin{abstract}
In high power converter design, low-inductance busbar connecting DC capacitors and power devices is the main concern to improve the quality of the whole power electronics system. This paper analyzes the impact of layernumber on the stray inductance of busbar taking a subway traction converter as example. The method of partial element equivalent circuit and the Q3D software are used to extract the stray inductance. The simulation and experimental results show that the stray inductance of three-layer busbar is lower than two-layer busbar with other same conditions.
\end{abstract}

Keywords: High-power converter, Busbar, Stray inductance, Number of layer.

\section{INTRODUCTION}

In modern high-power converters, the stray inductance existing in the commutation loop should be as low as possible considering safe and high-efficiency operation of switch devices and converters [1]. The oversize stray inductance distributing on the DC-busbar, which links DC capacitor bank to power devices, may bring excessive transient voltage overshoots. The voltage overshoots can result in increasing heating/power losses, high voltage stress and exceeding of the device safe operating area [3]. Thence, it is significant to make out a low-inductance busbar structure in early design stage.

There is extensive literature on the study of DC busbar to decrease the stray inductance in different aspects [1-6]. Huiqing [4] compared various busbar shapes in terms of internal and external impedance to show the superior performance of a parallel plate structure. Pasterczyk [5] discussed the application of a laminar busbar structure. A laminatedstructure bus bar provides as low effective inductance as possible for a converter. In fact, the layer-number of busbar should affect the value of the stray inductance, which is worthy of in-depth research. The paper [7] did some research on most important parasitic parameters of capacitor tank in converter and the effect on switching transient process. In fact, the value of stray parameters exiting in the DC-link busbar is a little larger than the parasitic parameters of capacitor [8].

In this paper, we focus on the impact of layer-number on the stray inductance of busbar in order to minimize the parasitic inductance of the busbar used in high power con

*Address correspondence to this author at the School of Electrical Engineering and Automation, He'nan Polytechnic University, 2001 Century Avenue, Jiaozuo (454003), Henan, P.R. China; Tel: 86+13693916259;

Fax: 0391-3987555; E-mail 1:zyfny@hpu.edu.cn verters. A subway traction converter is taken as an example to analyze the impact, including two-layer busbar and threelayer busbar. Firstly, the analytical model of multi-layer busbar is set up to obtain the stray inductance. Then, some simulation and experimental results are given to validate the conclusion further.

\section{THE PARASITIC PARAMETERS OF DC-LINK BUSBAR}

Much effort has been done to build a proper busbar model for electrical analysis. The paper $[9,10]$ proposed an analytical model of interconnect parasitic inductance on MOSFET switching characteristics and on high power semiconductor modules. In high-power converter the DC-link busbar usually is made up of two electric layers and one dielectric layer between the electric layers as shown in Fig. (1). The classical equivalent circuit model of busbar is given in Fig. (2), which has been proposed to evaluate the electromagnetic performance effectively [2].

One can see that the stray parameters existing in a busbar include resistance $\left(R_{1}, R_{2}\right)$, self-capacitor $\left(C_{1}, C_{2}\right)$, selfinductance $\left(L_{1}, L_{2}\right)$, mutual capacitance $\left(C_{12}\right)$, conductivity $(\mathrm{G})$ and mutual inductance $\left(M_{12}\right)$. The most important parameters which affect the converter-characteristics are mutual capacitor and the total inductance. Here, our study will focus on the stray inductance of busbar in order to minimize the overshoot voltage caused by parasitic inductance of the busbar.

Suppose that the mechanical dimensions of the busbar in Fig. (1) are: length $[l] \mathrm{m}$, width $[w] \mathrm{m}$, thickness of the plate $[h] \mathrm{m}$ and distance between the two plates $[d] \mathrm{m}$.Then, the mutual inductance between the up busbar-plat and the down busbar-plat can be approximately calculated by the following formula: 


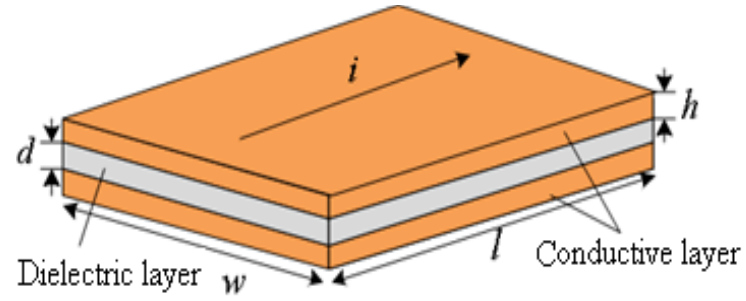

Fig. (1). Mechanical model of common busbar.

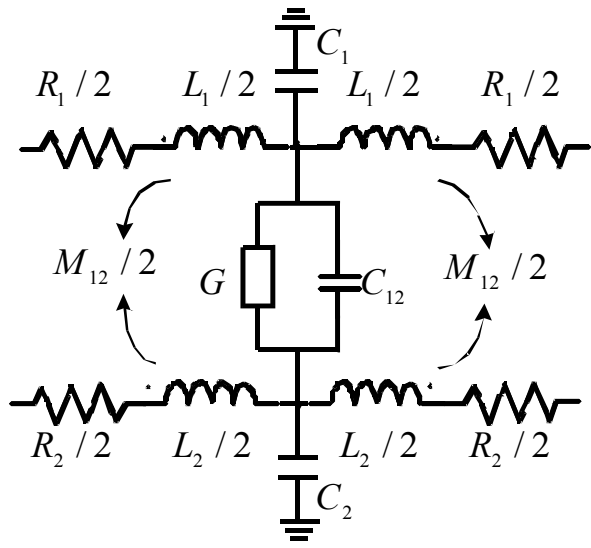

Fig. (2). The equivalent circuit model of busbar.

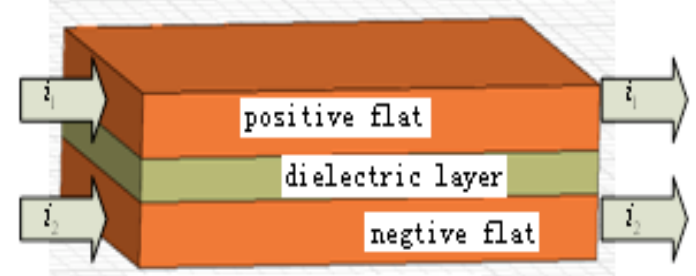

Fig. (3). Analytical model of two-layer busbar.

$M_{12}=\Psi_{12}=\frac{\mu_{0} \mu_{r} l h}{\pi \sqrt{4(d+h)^{2}+k w^{2}}} \cos \varphi$

where, $\mu_{0}, \mu_{\mathrm{r}}$ are the vacuum permeability and the relative permeability of the material of the insulating layer; $k$ is the correction coefficient and $\varphi$ is the angle between the direction of the two current plates.

Since the skin effect and proximity effect depending on frequency will reduce the internal flux, the inductance in the high frequency will be reduced, even neglected. But for low frequency operation in terms of the power converter, its internal inductance accounts for much. The external inductance is related to busbar geometric and independent of frequency. The internal inductance, the outer inductance and the total inductance can be solved as follows according to Maxwell equations:

$$
\left\{\begin{array}{l}
L_{i}=\frac{\mu_{0} \mu_{r}}{8 \pi} l \\
L_{e}=2 \mu_{0} \mu_{r} \frac{h l}{\pi(h+w)} \quad(d<<h 11 d+h<<w) \\
L=L_{i}+L_{e}=\frac{\mu_{0} \mu_{r} l}{\pi}\left(\frac{1}{8}+\frac{2 h}{h+w}\right)
\end{array}\right.
$$

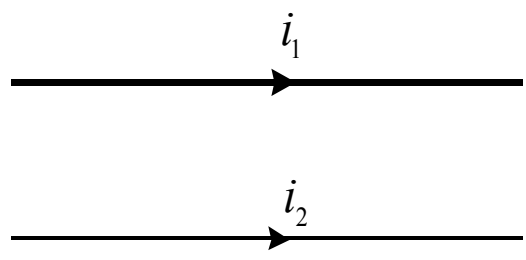

Fig. (4). The circuit model of two-layer busbar.

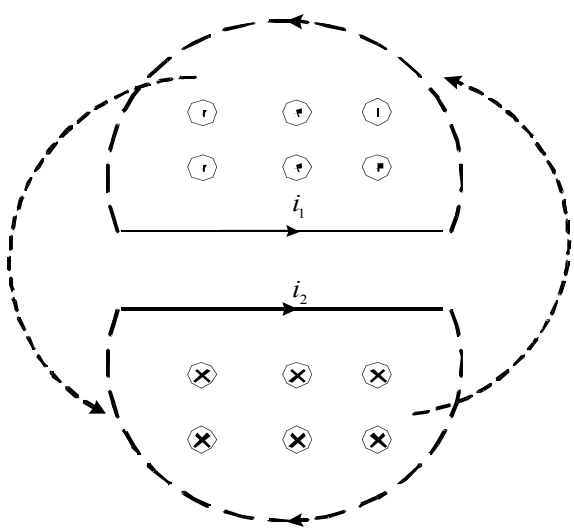

Fig. (5). The magnet coupling of parallel busbar.

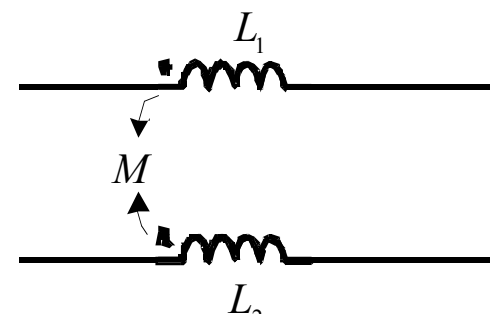

Fig. (6). The stray-inductance model of the busbar.

As it can be seen from the formula, the stray selfinductance is proportional to the length of the busbar, of reverse change relationship with the busbar width, and is to positively change relationship with the thickness.

\section{ANALYTICAL MODEL OF TWO-LAYER BUSBAR}

As we know, H-bridge converter is essential form to construct other complicated high-power converter. In H-bridge the power device can be a single-switch device or a doubleswitch device as well. If a double-switch device is adopted, then the busbar connecting DC capacitance and semiconductor switch is two-layer structure as shown in Fig. (3). The busbar includes positive flat, negative flat and dielectric layer.

Fig. (4) shows the circuit model of two-layer busbar, which is like two parallel wires with current. According to Faraday's law each wire with current will produce magnetic field. At the same time the two magnetic fields may couple with each other to induce self-inductance and mutualinductance. Fig. (5) gives the magnet coupling of parallel busbar and Fig. (6) is the stray-inductance model of the busbar. On the basis of Fig. (6) the total stray inductance of the busbar can be calculated by the following formula, 


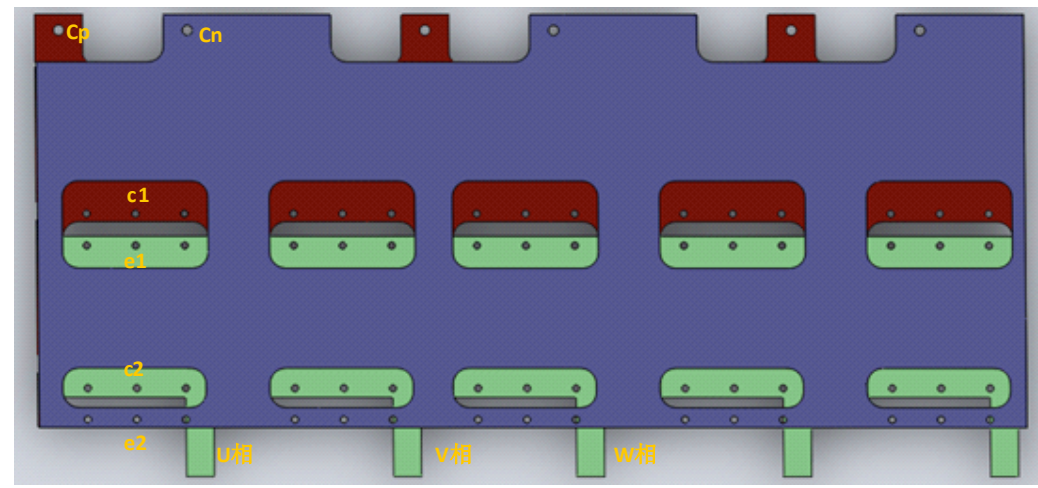

Fig. (7). The diagram of a three-layer busbar.

$$
L_{\Sigma}=L_{1}+L_{2}-2 M
$$

where, $L_{1}$ and $L_{2}$ are stray self-inductance of positive plate and negative plate, respectively. $M$ is the mutual-inductance of $L_{1}$ and $L_{2}$.

\section{ANALYTICAL MODEL OF THREE-LAYER BUS- BAR}

When a single-switch is utilized as the power device in high-power converters, the DC busbar usually adopts threelayer structure. Fig. (7) gives a three-layer busbar used in some subway traction converter, where the blue plate, the green plate and the red plate are positive busbar, phase busbar and negative busbar. The phase busbar connects the up device and the down device in the same bridge-arm and outputs AC current.

Fig. (8) shows the connection relation between the device terminals and the stray inductance. Fig. (9) gives the cou-

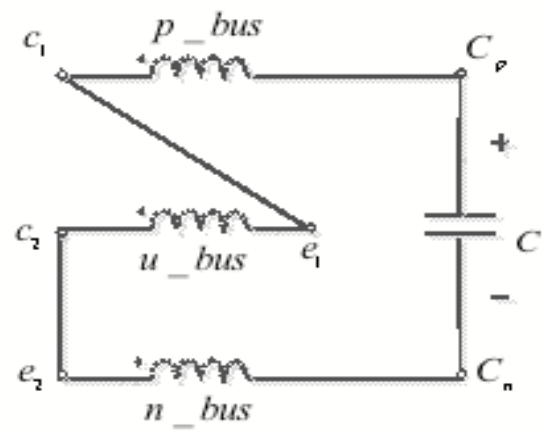

Fig. (8). The connection of terminals and the inductance.

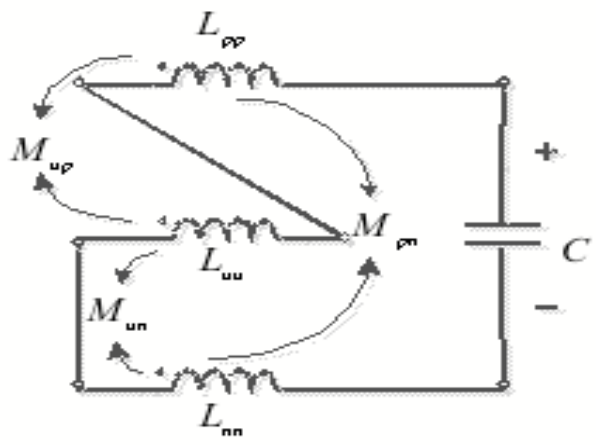

Fig. (9). The coupling of different inductance.

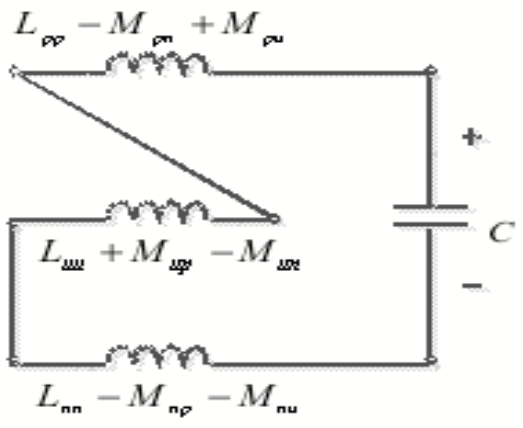

Fig. (10). The stray-inductance model of the busbar.

pling situation of different stray inductances produced by different layer busbars. Based on Fig. (9) the strayinductance model of the three-layer busbar can be given as shown in Fig. (10), where coupling inductance has been decoupled.

$$
L_{b u s 3}=\Sigma L=L_{p p}+L_{n n}+L_{u u}-2 M_{p n}-2 M_{u n}+2 M_{u p}
$$

Where, $L_{\text {bus } 3}$ is the total stray inductance of three-layer busbar. $L_{\mathrm{pp}}, L_{\mathrm{nn}}$ and $L_{\mathrm{uu}}$ are the self-inductance of positive busbar, negative busbar and u-phase busbar, respectively. $M_{\mathrm{pn}}$, $M_{\mathrm{pu}}$, and $M_{\text {nu }}$ are the mutual-inductance between different plates. Furthermore, the following formula can be obtained.

$M_{p n}=M_{n p} M_{p u}=M_{u p} M_{u n}=M_{n u}$

When the IGBT module is double-switch device, there is no UVW-phase output-layer busbar. According to the analysis before the stray inductance of the two-layer busbar can described as

$$
L_{b u s 2}=L_{p p}+L_{n n}-2 M_{p n}
$$

Comparing formula (6) and formula (4) one can get the stray-inductance variation with three-layer busbar as formula (7),

$$
\Delta L=L_{b u s 3}-L_{b u s 2}=L_{u u}+2 M_{u p}-2 M_{u n}
$$

Formula (7) shows that for given converter structure smaller U-phase output-layer stray-inductance $L_{\mathrm{uu}}$ and greater mutual inductance $M_{\mathrm{nu}}$ between negative busbar and U-phase busbar can be obtained. On the other hand, the mutual inductance $M_{\text {pu }}$ between positive busbar and U-phase busbar is very small because the current flowing in positive 


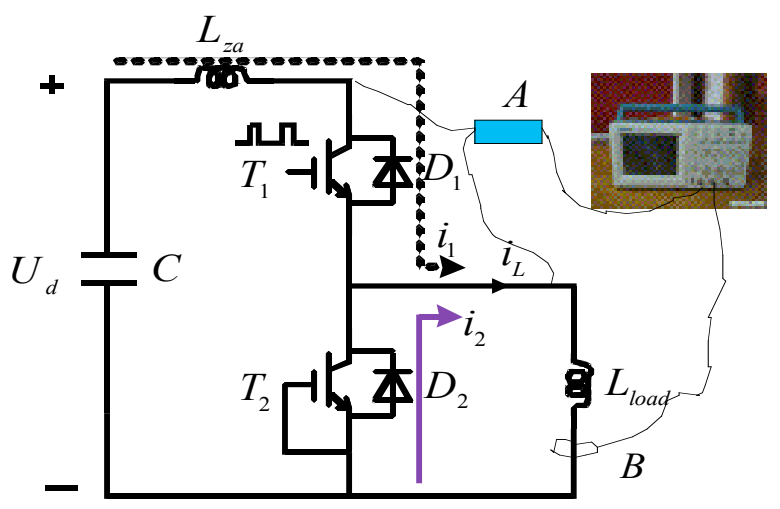

Fig. (11). The test circuit of the stray inductance.

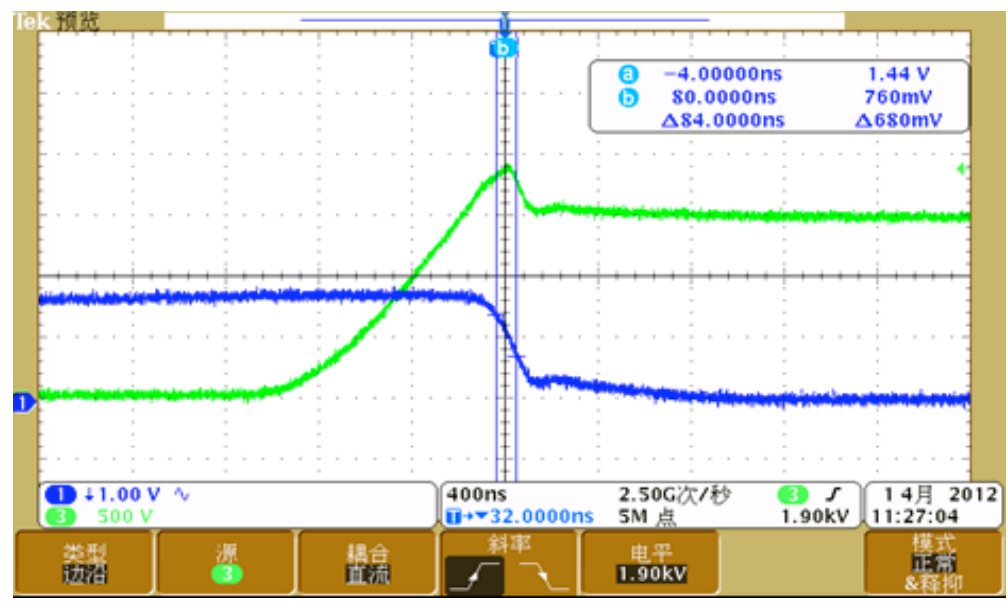

Fig. (12). The waveform of $u_{\mathrm{ce}}$ and $i_{\mathrm{c}}, \Delta u_{\mathrm{ce}}=400 \mathrm{~V}$.

Table 1. The stray Inductance of each Arm in Different Schemes

\begin{tabular}{|c|c|c|c|c|c|}
\hline Stray induc-tance $(\mathbf{n H})$ & $\mathbf{a r m 1}$ & $\mathbf{a r m} \mathbf{2}$ & $\mathbf{a r m 3}$ & $\mathbf{a r m 4}$ & 123.1 \\
\hline \hline $\begin{array}{c}\text { Two-layer } \\
\text { busbar }\end{array}$ & 145.9 & 126.3 & 124.1 & 164.7 \\
\hline $\begin{array}{c}\text { Three-layer } \\
\text { busbar }\end{array}$ & 137.3 & 123.4 & 122.1 & 119.6 & 151.4 \\
\hline
\end{tabular}

busbar hardly couples with the current flowing in phase busbar. Therefore, through appropriate design of phase busbar the following relation can be achieved,

$$
\Delta L<0
$$

It is to say that the stray inductance can be reduced further by good design of three-layer busbar. The good design implies that the phase busbar should be as wide as possible and as short as possible, which will decrease the selfinductance.

\section{SIMULATION AND EXPERIMENTAL RESULTS}

To validate the conclusion drawn in the third section some simulation and experiments are given on a three-layer busbar used in subway traction converter with the power of 3WM. The simulation software is Ansoft Q3D, which can extract the stray inductance of different busbar structures conveniently. Table $\mathbf{1}$ gives the simulation results for the two-layer busbar and three-layer busbar, respectively. From Table 1, one can see that the stray inductance of three-layer busbar is smaller than that of two-layer busbar for each bridge arm, which matches well with the analysis before. The maximum decrease comes out on arm5 and is equal to $13.3 \mathrm{nH}$ because of the optimized layer number.

Fig. (11) shows the experimental circuit to test the stray inductance, where A and B are high-voltage probe and Rogowski coil, respectively. And Fig. (12) gives the experimental waveform of the up power device in arm1 under three-layer busbar. One can see that the overshoot voltage is about $400 \mathrm{~V}$, and the work current is equal to $1200 \mathrm{~A}$. And the computed stray-inductance of the busbar $\left(L_{\mathrm{za}}\right)$ is approximately $134 \mathrm{nH}$ by the mathematical formula as (9). The simulation and experimental results match well. 
$L_{z a}=\frac{U_{o v}}{I_{n}} t_{f}$

Where, $U_{\text {ov }}$ is the overshoot voltage born by the switch device which changed from turn-on to turn-off, $I_{\mathrm{n}}$ is the electrical current flowing in the H-bridge circuit when the $\mathrm{H}$-bridge works normally, and $t_{\mathrm{f}}$ is the time duration for the current from $I_{\mathrm{n}}$ to zero.

\section{CONCLUSIONS}

Stray inductance is an important concern in high power converter design. Low inductance and oscillation planar busbar have played a significant role in reducing EMC problems caused by stray inductance.

In high-power converters with more and more use of single-switch power device, a three-layer busbar is adopted. The stray inductance of three-layer busbar can be smaller than two-layer busbar through appropriate design because the coupling inductance reduces the total stray-inductance. The appropriate design means that the phase busbar should be designed as wide as possible and short to decrease the self-inductance. And the smaller inductance brings a lower voltage-overshoot during the device turning off.

\section{CONFLICTS OF INTEREST:}

The authors confirm that this article content has no conflicts of interest.

\section{ACKNOWLEDGEMENTS}

Declared none.

\section{REFERENCES}

[1] Z. Yi-feng and GE Qiong-xuan. "Study on busbar-structure for prototype of the high-speed railway traction converter". Proceedings of 2011 International Conference on Electrical and Control Engineering, pp. 3177-3180, 2011

[2] C. Caponet, F. Profumo, R. W. De Doncker and A. "Tenconi. Low stray inductance bus bar design and construction for good EMC performance in power electronic circuit", IEEE Trans on Power Electron, vol. 17, no. 2, pp.225-231, 2002.

[3] Z. Wang and G. Chen. Study on planar busbar regarding stray inductance minimization and oscillation suppression for high power converter, Sustainable Power Generation and Supply, SUPERGEN '09. International Conference. 2009, pp. 1-7.

[4] H. Wen, X. Wen, J. Liu, X. Guo and F. Zhao. A low-inductance high-frequency film capacitor for electric vehicles, International Conference on Electrical Machines and Systems, ICEMS. 2007, pp. 2046-2050.

[5] R.J. Pasterczyk, C. Martin, J.-M. Guichon and J.-L. Schanen, Planar busbar optimization regarding current sharing and stray inductance minimization, European Conference on Power Electronics and Applications, pp. 90- 95, 2005.

[6] F. Zare and G.F. Ledwich. "Reduced layer planar busbar for voltage source inverters [J]", Power Electron, IEEE Trans. vol. 17, no. 4, pp. 508-516, 2002.

[7] L. Fangzheng, S. Xudong, H. Lipei and J. Jianguo. Parasitic parameters of capacitor tank in converter and the effect on switching transient process[J].Vehicle Power and Propulsion Conference, VPPC '09. IEEE pp. 736-739, 2009.

[8] Z. Lounis, I. Rasoanarivo and B. Davat, "Minimization of wiring inductance in high power IGBT inverter [J]" Power Deliv, IEEE Trans. vol. 15, no. 2, pp. 551-555, 2000.

[9] Y. Xiao, H. Shah, T. Chow, and R. Gutmann. Analytical modeling and experimental evaluation of interconnect parasitic inductance on MOSFET switching characteristics. 2004, pp. 516-521.

[10] P. Böhm, E. Falck, J. Sigg and Wachutka, G. Continuous Field Analysis of Distributed Parasitic Effects by Interconnects in High Power Semiconductor Modules. Proc. of SISPAD, Leuven, Belgium, 2008, pp. 340-343.

Received: July 04, 2013

Revised: July 07, 2013

Accepted: July 13, 2013

(C) Zhu et al.; Licensee Bentham Open.

This is an open access article licensed under the terms of the Creative Commons Attribution Non-Commercial License (http://creativecommons.org/licenses/by-nc/3.0/) which permits unrestricted, non-commercial use, distribution and reproduction in any medium, provided the work is properly cited. 